\title{
Electroencephalography as a Tool for Assessment of Brain Ischemic Alterations after Open Heart Operations
}

\author{
Elena Z. Golukhova, ${ }^{1}$ Anna G. Polunina, ${ }^{1}$ Natalia P. Lefterova, ${ }^{1}$ and Alexey V. Begachev ${ }^{2}$ \\ ${ }^{1}$ Bakulev Scientific Center of Cardiovascular Surgery, Russian Academy of Medical Sciences, \\ Leninsky Prospekt 156-368, Moscow 119571, Russia \\ ${ }^{2}$ Anaesthesiology and Intensive Care Department, Medical Center of the State Bank of Russia, Moscow 117593, Russia
}

Correspondence should be addressed to Anna G. Polunina, anpolunina@mail.ru

Received 6 September 2010; Revised 31 March 2011; Accepted 31 March 2011

Academic Editor: Halvor Naess

Copyright (C) 2011 Elena Z. Golukhova et al. This is an open access article distributed under the Creative Commons Attribution License, which permits unrestricted use, distribution, and reproduction in any medium, provided the original work is properly cited.

Cardiac surgery is commonly associated with brain ischemia. Few studies addressed brain electric activity changes after on-pump operations. Eyes closed EEG was performed in 22 patients (mean age: $45.2 \pm 11.2$ ) before and two weeks after valve replacement. Spouses of patients were invited to participate as controls. Generalized increase of beta power most prominent in beta-1 band was an unambiguous pathological sign of postoperative cortex dysfunction, probably, manifesting due to gamma-activity slowing ("beta buzz" symptom). Generalized postoperative increase of delta-1 mean frequency along with increase of slow-wave activity in right posterior region may be hypothesized to be a consequence of intraoperative ischemia as well. At the same time, significant changes of alpha activity were observed in both patient and control groups, and, therefore, may be considered as physiological. Unexpectedly, controls showed prominent increase of electric activity in left temporal region whereas patients were deficient in left hemisphere activity in comparison with controls at postoperative followup. Further research is needed in order to determine the true neurological meaning of the EEG findings after on-pump operations.

\section{Introduction}

Cardiac surgery is commonly associated with perioperative brain ischemia. Neuroimaging studies consistently demonstrated acute brain edema and global decrease of brain metabolism during first three days after on-pump surgery [1-4]. In addition, $20-45 \%$ of on-pump patients demonstrated multiple small ischemic lesions postoperatively [48 ]. Only $20 \%$ of patients with neuroimaging ischemic lesions showed clinical signs of stroke or acute encephalopathy. Nevertheless, the majority of on-pump patients reported memory decrease several months or even several years after surgery $[9,10]$. Neuropsychological studies consistently confirmed mild cognitive decline in the majority of cardiac surgery patients at discharge and in $7-69 \%$ of patients at 1-3 months followup after surgery [11]. Hence, mild brain ischemic injury is common after on-pump surgery appearing as postoperative cognitive dysfunction. Overall, total volume of brain ischemic alterations correlated with clinical symptoms in the majority of neuroimaging studies $[7,8,12,13]$.

Many researchers pointed to the embolic genesis of the postoperative brain infarcts due to characteristic distribution of the latter ones $[12,14]$. Significant associations between microembolic load and severity of postoperative brain injury were consistently shown $[2,15,16]$. In our relatively young patient cohort we found the threshold association between microembolic load and postoperative delirium, that is, patients with delirium were characterized by more than 900 microembolic signals during on-pump period [17]. Postoperative cognitive dysfunction was shown to be associated with intraoperative cerebral microembolic load in a range of studies as well [18-20]. Important, Stygall and colleagues [21] determined the association between cognitive decline at 5 years after CABG and the number of intraoperative microemboli in their study. Hence, cerebral microemboli appear to be a primary cause of brain ischemia in the majority of patients undergoing on-pump operations. 
Microemboli are observed during on-pump procedures in nearly all patients $[20,22]$. The number of microemboli considerably varies in different cases being the largest in open heart operations. In the study of Abu-Omar and colleagues [23], open heart procedures were associated with a 22-fold increase in microemboli in comparison with off-pump group. Several studies showed a 2-5-fold increase in microemboli during open heart operations in comparison with on-pump coronary surgery [20, 23-25]. It is not unexpected that prevalence of acute postoperative encephalopathy and cognitive dysfunction was reported to be higher after valve operations in comparison with coronary surgery $[20,26]$.

The inventor of electroencephalography (EEG), Hans Berger, hypothesized brain electric oscillations to be directly associated with cognitive activity [27]. However, until computer processing of EEG data became available, this suggestion was rejected by the majority of clinical neurologists and even scientists. Moreover, such striking EEG phenomenon as alpha-rhythm was widely interpreted as a "resting state" activity resulting from inhibitory thalamic effects, and slowwave oscillations were considered to be an indicator of pathological or somnogenic brain states. Recent computer EEG studies showed that only small proportion of cortical alpha activity related to corticothalamic interactions, and the majority of alpha-band oscillations originated due to functional interconnectivity of cortical regions [28, 29]. The direct associations between slow-wave oscillations and cognitive activity were shown in neurologically healthy individuals as well $[28,30]$. At present, it is widely accepted by the psychophysiological community that slow-wave activity, alpha- and high-frequency (beta and gamma) oscillations in healthy awaken subjects are directly involved in cognitive processing [28, 30, 31].

Brain oscillations during "resting" state were consistently shown to highly correlate with intelligence and a range of cognitive functions [31-33]. Clearly, the situation of EEG registration is completely unusual for the majority of patients and healthy subjects, and therefore induces intensive cognitive processing including internal representations and memorizing of a new environment of a neurophysiological lab, imaging of a personal localization, and associations of the present experience and past memories. Magnetic resonance functional neuroimaging demonstrated prominent activation of a range of brain structures (medial prefrontal cortex, posterior cingulate, inferior parietal cortex, precuneus, and medial temporal cortex) during awaken eyes closed state, which was conventionally called "resting" condition [34-36]. Hence, contemporary spectral EEG studies evidence that electric brain oscillations during "resting" state predominantly relate to cortex cognitive processing. Therefore, computer EEG is a perspective tool for assessment of mild postoperative ischemic brain alterations appearing as cognitive dysfunction.

Studies using intraoperative computer EEG monitoring evidence that brain electric activity demonstrates moderate sensitivity (0.55) and high specificity (1.0) in detecting brain ischemic alterations [37]. Decrease in EEG amplitude and/or EEG slowing manifest when mean cerebral blood flow falls below $22 \mathrm{ml} / 100 \mathrm{~g} / \mathrm{min}$. Initial decrease in fast activities (alpha and beta) is followed by appearance of delta rhythms. A further decrease in perfusion leads to flattening of the EEG activity [37]. Nevertheless, flattening of brain electric activity is typical for brain cooling during bypass and for general anesthetic effects [38]. Although, effects of brain ischemia and general anesthesia on brain electric activity are somewhat similar, intraoperative EEG characteristics appear to be predictive for postoperative cognitive dysfunction. Gugino and colleagues [39] found significant associations between intraoperative characteristics of brain electric activity and postoperative decrement of performance on two or more neuropsychological tests in 2-3 months after on-pump operations.

A handful of studies evaluated brain electric activity in patients after cardiac operations. Evoked auditory cognitive potential (P300) was consistently shown to be deteriorated during first weeks after valve and on-pump coronary operations [40-43]. Importantly, several studies found significant associations between severity of cardiac operations and postoperative impairment of evoked brain electric activity [41-43]. For instance, Grimm and colleagues [43] observed impairment of P300 after mitral valve replacement but not after valve repair. Zimpfer and colleagues [42] found prolongation of $\mathrm{P} 300$ in four months after aortic valve replacement but not after CABG. Kilo et al. [41] reported impairment of P300 after on-pump but not after off-pump CABG. The group means differed significantly at followups in all cited studies. Overall, the studies of evoked cognitive potentials showed that the operations with larger embolic load (valve replacement versus valve repair or CABG; onpump CABG versus off-pump CABG) were associated with greater postoperative impairment of brain electric activity.

Characteristics of spontaneous (resting state) brain electric activity were demonstrated to change after cardiac operations as well [44-47]. Zeitlhofer and colleagues [44] found slight delta-theta relative power increase, alpha decrease and beta increase in 10 days after open heart surgery. In contrast, Hauser et al. [45] reported significant decrease of beta along with alpha-2 power in children after open heart surgery. Vanninen and colleagues [47] found slowing of background activity and increase of relative slow-wave activity at bipolar central and posterior derivations at three months after CABG. EEG slowing did not correlate with the occurrence of new cerebral lesions in the postoperative MRI scans or with deterioration in neuropsychological test performance in that study. Nevertheless, Toner and colleagues [46] reported significant decrease of relative delta and theta power at both 7-day and 2-month followups after CABG. Significant association between postoperative EEG slowing and neuropsychological deficits was found in the latter study. It should be noted that the discrepancies between findings in the cited reports may be partially attributed to the use of relative power parameters, which are less reliable EEG measures in comparison with absolute power [31]. Absence of repeated evaluations of healthy controls is a shortcoming of both studies as well.

Using EEG for repeated evaluations of neurological patients is problematic due to obligatory changes of brain 
electric activity at followups in healthy subjects. This electrophysiological phenomenon is widely known for evoked potentials $[48,49]$ and was less investigated for "resting" brain activity. Corsi-Cabrera and colleagues [50] reported significant increase of theta power and decrease of beta2 power at eyes closed condition, and decrease of alpha and beta at eyes open condition at 1-month followup in comparison with the first assessment in healthy women. Angelakis et al. [51] showed significant increase of alpha peak frequency at followup in healthy subjects. In our study of healthy subjects [52], presented here as a control group, we observed significant decrease of alpha and theta- 2 power along with changes of alpha- 1 and alpha- 2 mean frequencies in right hemisphere at 2-week followup. In addition, increase of delta-2, theta and beta power was prominent in left temporal region in the majority of subjects. Slowing of delta1 mean frequency in left hemisphere and slowing of theta2 frequency in temporal region were also characteristic for followup EEG recordings. Hence, physiological changes of brain electric activity at repeated evaluations are prominent, and this fact should be correctly treated during clinical longitudinal studies using EEG.

The primary aim of the present study was to test the possibility of using the computer EEG as a tool for detecting and evaluating mild neurological alterations in patients after open heart operations. Here we present the data of the repeated EEG assessments of cardiac surgery patients in comparison with healthy controls. In addition, patients were repeatedly evaluated by a battery of neuropsychological tests, and the interrelationships between postoperative brain electric activity and cognitive changes are currently being analyzed and are going to be presented elsewhere. As correlations between brain electric activity and separate cognitive domains are region specific $[32,33]$, we investigated both global and regional postoperative dynamics of brain electric activity. Post hoc analyses at separate leads were undertaken as well, because this approach consistently showed similar correlations between performance on cognitive tests and brain electrical oscillations [32, 33]. We studied eight frequency bands instead of the usual four ones (delta, theta, alpha, and beta), as the narrow bands demonstrated more reliable neurophysiological correlates in a range of studies $[32,53,54]$. Both eight bands' power and mean frequency parameters were analysed as mean frequency was consistently shown to be a highly informative measure in investigating cognitive versus EEG associations [32, 33]. In addition, we tested associations between postoperative brain electric activity changes and the presence of risk factors of excessive intraoperative cerebral microembolic load.

\section{Materials and Methods}

2.1. Subjects. A total of 25 patients were included into the study; however, followup EEG recordings were completed only in 22 subjects. Inclusion criteria were age 16-59 years old and preoperative cardiac ejection fraction $>40$. Exclusion criteria were emergency and reoperative surgical procedures; previous cerebrovascular accident or other neuropsychiatric disorder; serious concomitant noncardiac disease. Ten spouses of patients were invited as controls; however, only eight of them returned for a followup. The preoperative and intraoperative characteristics of patients and demographic characteristics of controls are presented in Table 1.

2.2. Study Design. The present study protocols were reviewed and approved by the academic council of Bakulev's cardiovascular surgery center. The study design was explained to patients, and each patient gave informed consent to participate. Patients underwent clinical, EEG, and neuropsychological evaluation 2-3 days before surgery. Clinical examination included M-mode two-dimensional echocardiography for measuring a left ventricular end systolic dimension (absolute value was not normalized), because an enlarged left ventricular was associated with a high risk of elevated intraoperative cerebral microembolism in our previous study [55]. MiniMental State Examination was applied to evaluate overall cognitive status. In addition, subjects performed a set of cognitive tests (the data will be published elsewhere). The postoperative assessment was performed in 10-15 days after surgery. Controls were reevaluated with a 2-week interval as well.

2.3. Anesthesia, CPB, and Surgical Management. The protocols of anesthesia and surgical techniques were standardized. Diazepam and morphine served as premedication. Anesthesia was induced and maintained with propofol, fentanyl, and pancuronium. The perfusion apparatus consisted of the Stökert S3 roller pump (Germany), DIDECO-703 membrane oxygenator (Italy), and a $40 \mu \mathrm{m}$ arterial filter. Nonpulsatile pump flow rates were maintained between 2.4 and $2.6 \mathrm{~L} * \mathrm{~min}^{-1} * \mathrm{~m}^{-2}$, and mean perfusion pressure at $60 \mathrm{~mm} \mathrm{Hg}$. The operations were accomplished during moderate hypothermia $\left(28^{\circ} \mathrm{C}\right)$. All patients underwent median sternotomy, the aorta was cross-clamped and the heart was arrested with anterograde cold pharmacological cardioplegia by solution of custodiol. Topical ice saline was used as an adjuvant to myocardial protection. Aortic valve replacement was performed in 9 patients. Mitral valve was replaced in 10 patients. And 3 patients underwent combined valve surgery. Overall, the patients uneventfully underwent operations on aortic and/or mitral valve. Three patients demonstrated transitory mild psychotic symptoms (visual hallucinations and disorientation) during first postoperative day.

2.4. EEG Recordings and Analysis. Eyes closed resting EEG data were collected from the 21 monopolar electrode sites of the international 10/20 system (Fp1/Fp2, F3/F4, C3/C4, P3/P4, O1/O2, F7/F8, T3/T4, T5/T6, Fpz, Fz, Cz, Pz, Oz), referred to linked earlobes. EEG signal was amplified using EEG machine (Neuron-Spectr 4/EP, Neurosoft, Russia) with bandpass filter settings 0.5 and $35 \mathrm{~Hz}$. All signals were digitized online at a sampling rate of $200 \mathrm{~Hz}$. Electrode impedances were below $5 \mathrm{~K} \Omega$. Each recording comprised 710 min.

The resulting time series were inspected visually for body movements, eye blinks, eye movements, EMG, ECG, rheogram, and loose electrodes artifacts. Intervals identified 
TABLE 1: Subject characteristics and operative data.

\begin{tabular}{|c|c|c|c|}
\hline & Open heart surgery & Controls & $P$ \\
\hline Number of subjects & 22 & 8 & \\
\hline Male/female sex $(n)$ & $11 / 11$ & $1 / 7$ & NS \\
\hline Age (years) & $45.2 \pm 11.2$ & $39.4 \pm 16.6$ & NS \\
\hline Education (years) & $14.5 \pm 2.8$ & $15.4 \pm 3.4$ & NS \\
\hline MMSE at first assessment (score) & $27.3 \pm 2.6$ & $27.6 \pm 3.3$ & NS \\
\hline MMSE at followup (score) & $27.0 \pm 3.0$ & $28.1 \pm 3.7$ & NS \\
\hline History of hypertension $(n)$ & 6 & 0 & NS \\
\hline History of diabetes $(n)$ & 1 & 0 & NS \\
\hline History of atrium fibrillation $(n)$ & 7 & 0 & NS \\
\hline NYHA class III and IV $(n)$ & 8 & 0 & 0.046 \\
\hline Ejection fraction $(\%)$ & $62.3 \pm 7.0$ & & \\
\hline End systolic size of left ventricular (mm) & $35.6 \pm 0.8$ & & \\
\hline Mitral valve replacement $(n)$ & 10 & & \\
\hline Aortic valve replacement $(n)$ & 9 & & \\
\hline Aortic and mitral valve replacement $(n)$ & 3 & & \\
\hline Cardiopulmonary bypass time (minute) & $115.6 \pm 49.5$ & & \\
\hline Aortic cross-clamp time (minute) & $73.9 \pm 34.5$ & & \\
\hline Postoperative delirium $(n)$ & 3 & & \\
\hline
\end{tabular}

Data given as means and SD, unless otherwise indicated.

Abbreviations: $n$ : number of patients; NS: not significant; NYHA: New York Heart Association.

as disturbed by artifacts were excluded from the spectral analysis. Finally, $4 \mathrm{sec}$ with $50 \%$ overlap epochs were obtained from artifact-free EEG tracings and submitted to a fast Fourier transform. For each of the 21 monopolar derivations, absolute power and mean frequency were computed for the delta1 $(1-2 \mathrm{~Hz})$, delta2 $(2-4 \mathrm{~Hz})$, theta1 $(4-6 \mathrm{~Hz})$, theta2 $(6-8 \mathrm{~Hz})$, alpha1 $(8-10 \mathrm{~Hz})$, alpha2 $(10-13 \mathrm{~Hz})$, beta1 $(13-20 \mathrm{~Hz})$, and beta $2(20-30 \mathrm{~Hz})$ frequency bands.

2.5. Statistical Analysis. Statistical analysis was performed using SPSS software for windows (SPSS 17.0, Chicago, IL, USA). Repeated-measures analyses of variance (ANOVAs) were used to analyze EEG power and mean frequency data at 12 leads with regions, that is, laterality (central (F3/F4, C3/C4, P3/P4), temporal (F7/F8, T3/T4, T5/T6)), sagittality (anterior (F3/F4, F7/F8), medial (C3/C4, T3/T4), posterior (P3/P4, T5/T6)), hemisphere (left (F3, C3, P3, F7, T3, T5), right (F4, C4, P4, F8, T4, T6), and time (preoperative versus postoperative) as within-subject factors. First, repeatedmeasures ANOVAs included only EEG variables of patients, and time effects (global changes) and interaction of time with regions (regional changes) were tested. Second, the same ANOVAs were conducted using the data of patients and controls with a group as a between-subject factor. The time $*$ group and region $*$ time $*$ group interactions were tested. When significant region $*$ time or region $*$ time * group interactions were found, ANOVAs were conducted using only the data of the region of interest. Finally, posthoc analyses of dynamics of EEG variables at separate leads were conducted to test time $*$ group interaction. As a small proportion of EEG variables tended to be nonparametric, we preferred to apply Wilcoxon test to explore time effects at separate leads in patient group.
In order to test effects of cardiopulmonary bypass duration on postoperative dynamics of brain electric activity, the patient sample was split into two groups according to the median of on-pump time: $\mathrm{CPB}<100$ minutes and $\mathrm{CPB}$ $>100$ minutes. Repeated-measures ANOVAs were also used to analyze differences in dynamics of EEG power and mean frequency in two patient subgroups. The similar approach was used to explore effects of left ventricular end systolic size (LV) on postoperative brain electric activity. The patients were divided into two groups according to the median of LV: $\mathrm{LV}<35.5 \mathrm{~mm}$ and $\mathrm{LV}>35.5 \mathrm{~mm}$. Then repeatedmeasures ANOVAs were conducted with regions and time as within-subject factor and group according to LV size as a between-subject factor. Post-hoc analyses at separate leads were undertaken as well.

\section{Results}

3.1. Characteristics of Electrical Brain Activity before Surgery. Preoperatively, patients differed significantly from controls by lower beta-1 power in right hemisphere (hemisphere $*$ group interaction: $F=6.31, P=.018)$ with the similar trend for delta-2, theta-2, alpha-1, and alpha2 activity ( $F$ s $>3.5$, $P s<.10$, resp.). Group differences in total alpha-2 and beta1 mean frequencies reached significance as well $(F \mathrm{~s}=4.40$ and $6.43, P s=.045$ and .017 , resp.) with higher alpha-2 and lower beta-1 mean frequencies in the patient group in all brain regions.

3.2. Global Changes of Brain Activity after Open Heart Operations. Global changes of brain electric activity after open heart operations are summarized in Table 2. After surgery 

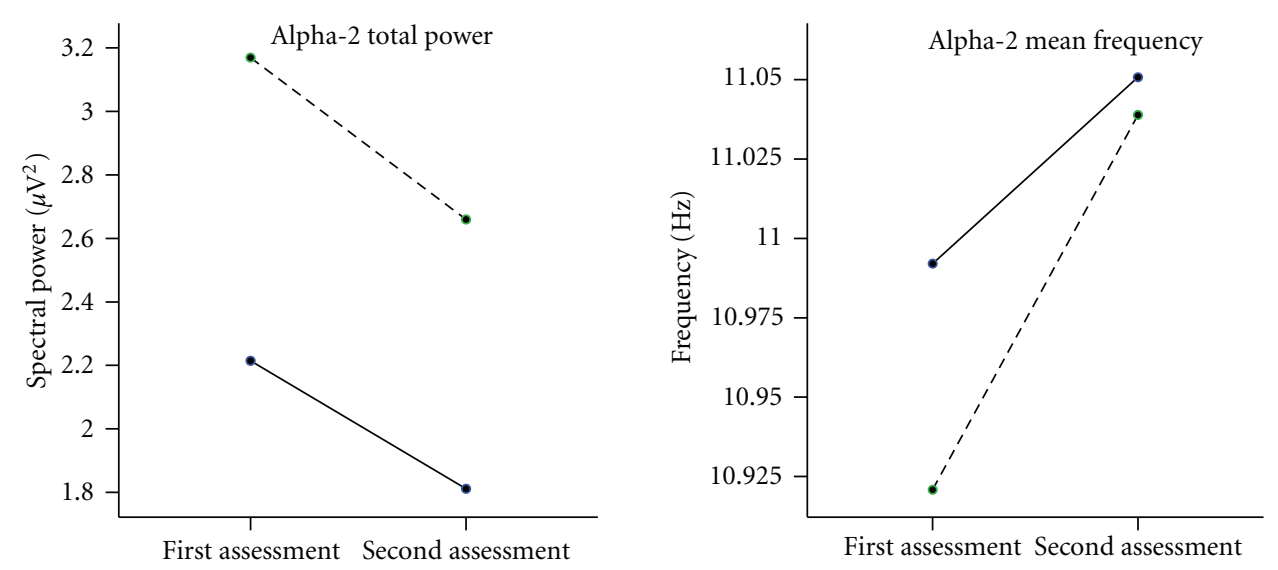

(a)
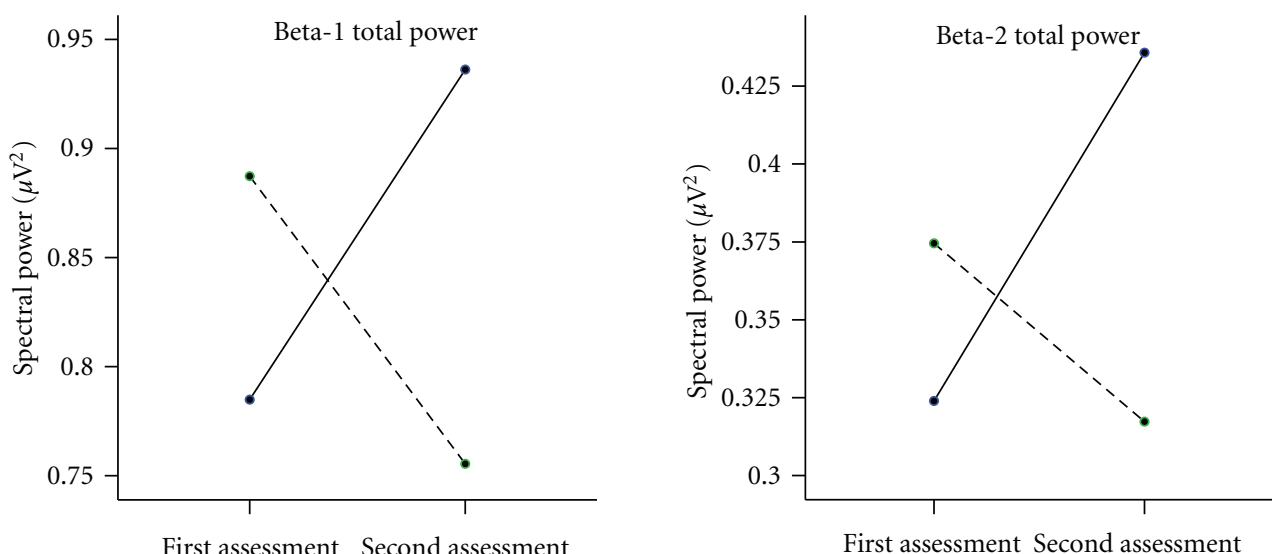

(b)
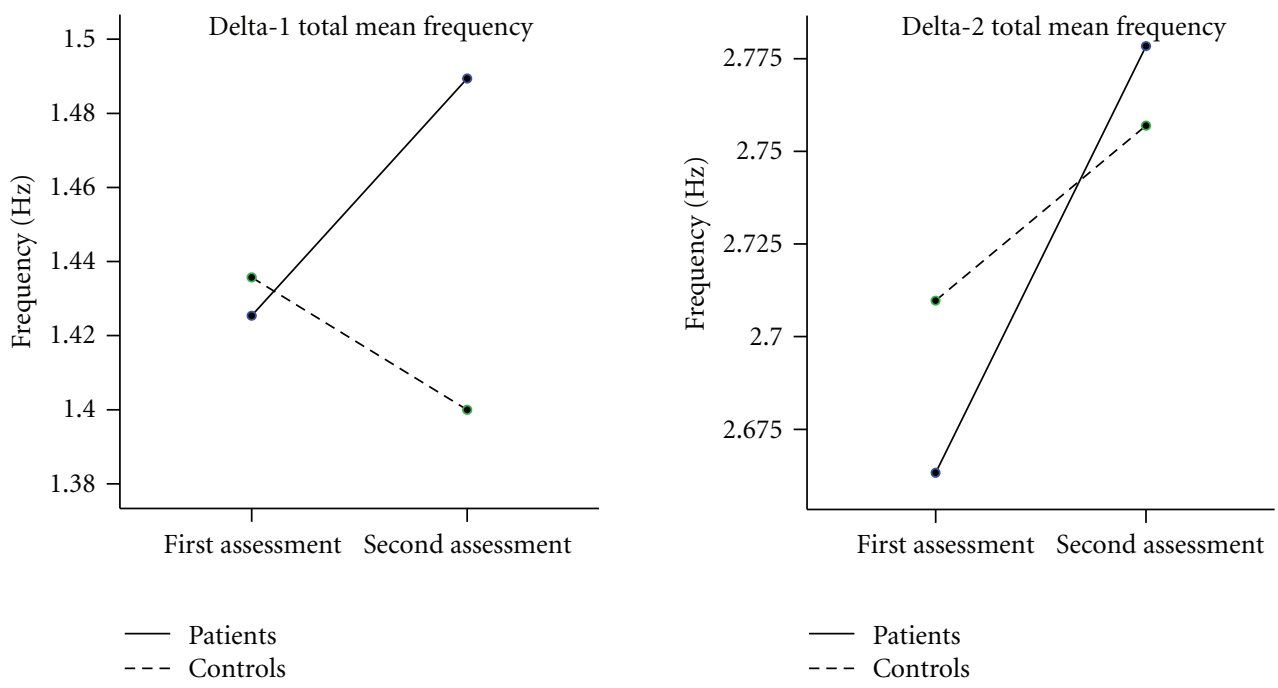

(c)

FIGURE 1: Global changes of alpha (a), beta (b), and delta (c) activity in patients after open heart operations and controls.

patients demonstrated significant decrease of alpha-2 power in all brain regions $(F=5.28, P=.032)$. Healthy controls showed significant decrease of alpha-2 power in right hemisphere, and therefore groups did not differ on global dynamics of alpha- 2 power $(F=0.037, P=.85)($ Figure $1(\mathrm{a}))$.
Nevertheless, groups differed on regional dynamics of alpha2 power due to somewhat larger decrease of alpha-2 power in right hemisphere in healthy controls and more prominent changes of this EEG variable in left hemisphere in patient group ( $F=6.90, P=.014)$. It should be noted, that global 
alpha-2 mean frequency increased in both groups at followup $(F=4.25, P=.049$; Figure $1(\mathrm{a}))$.

As opposite to controls, patients demonstrated global increase of beta-1 and beta-2 power ( $F$ s $=7.28$ and 5.42, $P s=.013$ and.030). Accordingly, patients differed significantly from controls on dynamics of beta- 1 total power $(F$ $=6.11, P=.020$; Figure $1(\mathrm{~b}))$ with the similar trend for beta-2 total power $(F=3.41, P=.076)$. Group effects were significant at C3, C4, Cz, P3, P4, Pz, O1, O2, F8, T4, and T6 (Fs $\left.>4.2, P_{\mathrm{S}}<.05\right)$ for changes of beta-1 power, and tended to be significant at Fpz, F3, C3, C4, Cz, P4, O1, T4, and T5 (Fs $>3.0, P$ s $<.10)$ for beta-2 power. It should be noted that maximal postoperative increase of beta-2 power was found at left posterior temporal and occipital region (leads T5 and O1, $z$ s $>2.5, P s<.01)$ along with concomitant increase of beta- 2 mean frequency at T5 $(z=2.05, P=.04)$. No significant postoperative changes or group effects on global or regional dynamics of beta- 1 or beta- 2 mean frequencies were found.

Delta-1 mean frequency showed postoperative increase in all brain regions in open heart patients $(F=15.8, P$ $=.001)$, and, accordingly, patients differed from controls on dynamics of total delta-1 mean frequency $(F=10.2, P$ $=.004$; Figure $1(\mathrm{c}))$. Postoperative changes of delta- 1 mean frequency at Fp2, C3, C4, P4, Pz, O1, O2, F7, T3, T5, F8, T4, and T6 reached significance $(z \mathrm{~s}<-2.00, P \mathrm{~s}<.05)$. Group effects were significant at C3, C4, P3, Pz, O1, O2, Oz, F7, and T3 (Fs $>4.3, P$ s $<.05)$. Maximal increase of delta-1 mean frequency was registered in left (T3) and right (F8) temporal derivations $(P \mathrm{~s}<.005)$.

In addition, patients showed significant increase of delta-2 mean frequency in all brain regions $(F=16.2, P$ $=.001)$. However, no group effects on dynamics of delta-2 mean frequency was found $(F=1.32, P=.26)$ as healthy controls demonstrated the similar global increase of this EEG parameter (Figure 1(c)).

3.3. Right Hemisphere Electrical Activity after Open Heart Surgery. As opposite to healthy controls, patients showed no regional changes of delta- 1 , delta- 2 , theta- 1 , theta- 2 , or alpha-1 power. Nevertheless, patients significantly differed from controls on dynamics of delta-1, delta-2. theta-2, and alpha-1 power in right hemisphere $(F s>5.4, P s<.03)$ due to significant decrease of brain activity power in right hemisphere in healthy subjects (Figure 2(a)). Analyses at separate leads showed group effects at T6 for delta-1; at C4, F8 and T6 for delta-2; at P4 and T6 for theta-2; at T4 for alpha-1 and alpha-2 (Fs $>4.5, P$ s $<0.05)$.

Dynamics of theta- 1 power was similar in left and right hemispheres in both groups $(F=0.51, P=.48)$. Nevertheless, groups differed on changes of theta-1 power in central region of right hemisphere $(F=5.11, P=.032$; Figure $2(\mathrm{~b}))$ due to postoperative increase of theta-1 power in the patient group. At the same time, patients and controls demonstrated similar increase of theta-1 power at right temporal derivations. Increase of theta-1 power at T4 and T6 was significant at postoperative followup in the patient group $(z \mathrm{~s}=-2.90$ and $-2.71, P s=.004$ and .007 , resp.). It should be noted, that delta-2 and theta-2 power increased at P4, T4, and T6 leads $(z \mathrm{~s}<-1.7$, Ps $<.08)$ in patients but not in controls at followup. No concomitant regional changes or group effects on theta- 1 and theta- 2 mean frequencies were found. Nevertheless, analyses at separate leads showed significant slowing of theta- 2 mean frequency at $\mathrm{C} 4$ and T6 in the patient group $(z s<-2.00, P s<.05)$ after surgery.

In addition, patients showed significant slowing of alpha1 mean frequency at $\mathrm{O} 2(z=-2.89, P=.004)$. However, this phenomenon was registered in healthy subjects as well, and analyses including both groups showed significant slowing of alpha-1 activity at O1, O2, and $\mathrm{Oz}$ at followup ( $F$ s > 7.0, Ps $\leq .01)$.

3.4. Left Hemisphere Electrical Activity after Open Heart Surgery. After surgery, patients differed from controls on dynamics of delta-2, theta-1, and theta- 2 power in central and temporal regions of left hemisphere $(F s>4.3, P s<.05)$ (Figure 3(a)). In central region power of slow-wave activity decreased in healthy controls and did not change in patients at followup. In temporal region, controls demonstrated increase of slow-wave activity power whereas patients did not show any changes. Analyses at separate leads showed group differences on dynamics of delta-1 $(F=4.07, P=.05)$ and delta-2 $(F=4.31, P=.048)$ power at left temporal derivation (T3). In addition, groups differed on dynamics of theta2 mean frequency in central and temporal region of left hemisphere $(F=5.30, P=.030)$. No group effects at separate leads analyses were found.

\subsection{Cardiopulmonary Bypass Length and Left Ventricular Size} Effects on Brain Activity. Patients with prolonged CPB were characterized by increase of alpha- 1 power in central region whereas patients with shorter CPB length showed decrease of alpha- 1 activity in central derivations $(F=8.94, P=.007)$ (Figure 4(a)). Group differences reached significance only at P3 $(F=5.73, P=.027)$ with the similar trend for $\mathrm{P} 4$ and $\mathrm{Pz}$ $(F s=3.63$ and $3.92, P s=.071$ and .062 , resp. $)$.

Patients with enlarged left ventricular size showed increase of beta-1 mean frequency in right hemisphere whereas patients with smaller left ventricular were characterized by decrease of this EEG parameter $(F=4.43, P=.048)$ (Figure 4(b)). Group differences in dynamics of beta- 1 mean frequency at $\mathrm{C} 4$ and $\mathrm{P} 4$ showed a trend to be significant $(F=$ 3.28 and $3.21, P_{s}=.085$ and .088 , resp.).

\section{Discussion}

In the present study we observed both physiological and pathological phenomena of brain electric activity dynamics after open heart operations. Indeed, some prominent postoperative EEG changes in our patient cohort did not differ from dynamics of brain electric activity in healthy controls. At the same time, a range of EEG parameters abnormally altered after cardiac operations, and the latter were highly probable signs of perioperative brain ischemia. 
TABLE 2: Global changes of BEA after open heart operation*.

\begin{tabular}{|c|c|c|c|c|}
\hline & $\begin{array}{l}\text { Patient group } \\
\text { dynamics** }\end{array}$ & Group effect*** & Local dynamics** & $\begin{array}{l}\text { Local group } \\
\text { effects } * * *\end{array}$ \\
\hline Total alpha-2 power decrease & $\begin{array}{l}F=5.28 \\
P=.032\end{array}$ & NS & $\begin{array}{l}\mathrm{F} 3, \mathrm{Fz}, \mathrm{C} 3, \mathrm{C} 4, \mathrm{Cz}, \mathrm{P} 3 \\
\mathrm{P} 4, \mathrm{Pz}, \mathrm{O} 1, \mathrm{O} 2, \mathrm{Oz}, \mathrm{T} 5\end{array}$ & $\begin{array}{l}\text { T4 (larger decrease } \\
\text { in controls) }\end{array}$ \\
\hline Total beta- 1 power increase & $\begin{array}{l}F=7.28 \\
P=.013\end{array}$ & $\begin{array}{l}F=6.11 \\
P=.020\end{array}$ & $\begin{array}{l}\mathrm{C} 3, \mathrm{C} 4, \mathrm{C} z, \mathrm{P} 3, \mathrm{P} 4 \\
\mathrm{P} z, \mathrm{O} 1, \mathrm{O} 2, \mathrm{~T} 3, \mathrm{~T} 5 \\
\mathrm{~F} 8, \mathrm{~T} 4, \mathrm{~T} 6\end{array}$ & $\begin{array}{l}\mathrm{C} 3, \mathrm{C} 4, \mathrm{Cz}, \mathrm{P} 3, \mathrm{P} 4 \\
\mathrm{Pz}, \mathrm{O} 1, \mathrm{O} 2, \mathrm{~F} 8, \mathrm{~T} 4 \\
\mathrm{~T} 6\end{array}$ \\
\hline Total beta- 2 power increase & $\begin{array}{l}F=5.42 \\
P=.030\end{array}$ & $\begin{array}{l}F=3.41 \\
P=.076\end{array}$ & $\begin{array}{l}\text { C3, P3, P4, Pz, O1, } \\
\text { O2, T3, T5, F8, T6 }\end{array}$ & $\begin{array}{l}\text { Fpz, F3, C3, C4, } \\
\text { Cz, P4, T4 }\end{array}$ \\
\hline $\begin{array}{l}\text { Total delta-1 mean frequency } \\
\text { increase }\end{array}$ & $\begin{array}{l}F=15.8 \\
P=.001\end{array}$ & $\begin{array}{l}F=10.2 \\
P=.004\end{array}$ & $\begin{array}{l}\text { Fp2, C3, C4, P4, Pz, } \\
\text { O1, O2, F7, T3, T5, } \\
\text { F8, T4, T6 }\end{array}$ & $\begin{array}{l}\mathrm{C} 3, \mathrm{C} 4, \mathrm{P} 3, \mathrm{Pz}, \mathrm{O} 1 \\
\mathrm{O} 2, \mathrm{Oz}, \mathrm{F} 7, \mathrm{~T} 3\end{array}$ \\
\hline $\begin{array}{l}\text { Total delta-2 mean frequency } \\
\text { increase }\end{array}$ & $\begin{array}{l}F=16.2 \\
P=.001\end{array}$ & NS & $\begin{array}{l}\text { Fp2, Fpz, F3, F4, C3, } \\
\text { C4, Cz, P4, O2, Oz, } \\
\text { F7, T5, F8, T4, T6 }\end{array}$ & $\mathrm{Fp} 2, \mathrm{Fpz}, \mathrm{Cz}, \mathrm{T} 4$ \\
\hline $\begin{array}{l}\text { Total alpha- } 2 \text { mean frequency } \\
\text { increase }\end{array}$ & $\begin{array}{l}F=4.25 \\
P=.049\end{array}$ & NS & P3, Pz, T3 & NS \\
\hline
\end{tabular}

${ }^{*}$ Findings at $P<.1$ are presented.

** Repeated measures ANOVAs or Wilcoxon tests included only patients.

$* * *$ Repeated measures ANOVAs included patients and normal controls.

TABLE 3: Hemisphere effects on electric activity after open heart operations*.

\begin{tabular}{|c|c|c|c|c|}
\hline & $\begin{array}{c}\text { Patient group } \\
\text { dynamics** }\end{array}$ & Group effect*** & Local dynamics** & Local group effects $* * *$ \\
\hline \multicolumn{5}{|c|}{ Right hemisphere } \\
\hline $\begin{array}{l}\text { Delta-1 power did not change } \\
\text { versus decrease in controls }\end{array}$ & NS & $\begin{array}{l}F=6.67 \\
P=.016\end{array}$ & NS & $\begin{array}{l}\text { C4, T4, T6 (decrease in } \\
\text { controls) }\end{array}$ \\
\hline $\begin{array}{l}\text { Delta- } 2 \text { power did not change } \\
\text { versus decrease in controls }\end{array}$ & $\begin{array}{l}F=3.62 \\
P=.071\end{array}$ & $\begin{array}{l}\mathrm{F}=5.95 \\
P=.022\end{array}$ & $\mathrm{P} 4, \mathrm{~T} 4$ (increase) & $\begin{array}{l}\mathrm{C} 4, \mathrm{~F} 8, \mathrm{~T} 4, \mathrm{~T} 6 \text { (decrease } \\
\text { in controls) }\end{array}$ \\
\hline $\begin{array}{l}\text { Theta- } 2 \text { power did not change } \\
\text { versus decrease in controls }\end{array}$ & NS & $\begin{array}{l}F=5.49 \\
P=.027\end{array}$ & $\begin{array}{l}\mathrm{P} 4, \mathrm{~T} 4, \mathrm{~T} 6 \\
\text { (increase) }\end{array}$ & $\begin{array}{l}\text { Fp2, C4, P4, T6 } \\
\text { (decrease in controls) }\end{array}$ \\
\hline $\begin{array}{l}\text { Alpha-1 power did not change } \\
\text { versus decrease in controls }\end{array}$ & NS & $\begin{array}{l}F=5.83 \\
P=.023\end{array}$ & F8, T4 (increase) & $\mathrm{T} 4$ (decrease in controls) \\
\hline $\begin{array}{l}\text { Theta-1 power increase in central } \\
\text { region }\end{array}$ & NS & $\begin{array}{l}F=5.11 \\
P=.032\end{array}$ & $\begin{array}{l}\mathrm{P} 4, \mathrm{O} 2, \mathrm{~T} 4, \mathrm{~T} 6 \\
\text { (increase) }\end{array}$ & P4 (decrease in controls \\
\hline \multicolumn{5}{|c|}{ Left hemisphere ${ }^{* * * *}$} \\
\hline $\begin{array}{l}\text { Delta-2 power increase in central } \\
\text { region and no change in } \\
\text { temporal region versus opposite } \\
\text { dynamics in controls }\end{array}$ & NS & $\begin{array}{l}F=4.42 \\
P=.045\end{array}$ & NS & T3 (increase in controls) \\
\hline $\begin{array}{l}\text { Theta-1 power did not change } \\
\text { versus significant changes in } \\
\text { controls }\end{array}$ & NS & $\begin{array}{l}F=4.33 \\
P=.042\end{array}$ & NS & NS \\
\hline $\begin{array}{l}\text { Theta- } 2 \text { power did not change } \\
\text { versus significant changes in } \\
\text { controls }\end{array}$ & NS & $\begin{array}{l}F=4.83 \\
P=.037\end{array}$ & NS & NS \\
\hline Alpha-2 power decrease & NS & $\begin{array}{l}F=6.90 \\
P=.014\end{array}$ & $\mathrm{~F} 3, \mathrm{C} 3, \mathrm{P} 3, \mathrm{O} 1, \mathrm{~T} 5$ & NS \\
\hline $\begin{array}{l}\text { Theta- } 2 \text { mean frequency } \\
\text { decrease in central region }\end{array}$ & NS & $\begin{array}{l}F=5.30 \\
P=.030\end{array}$ & NS & NS \\
\hline
\end{tabular}

${ }^{*}$ Findings at $P<.1$ are presented.

** Repeated measures ANOVAs or Wilcoxon tests included only patients.

*** Repeated measures ANOVAs included patients and normal controls.

$* * * *$ Statistics on interaction of time $*$ central/temporal region $*$ group factors in left hemisphere is presented. 
Delta-1 power

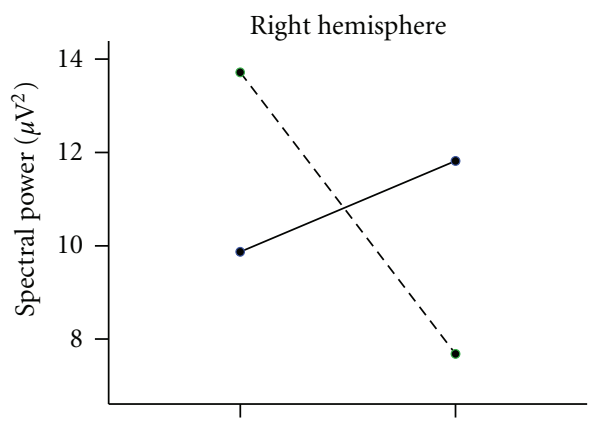

First assessment Second assessment

Theta-2 power

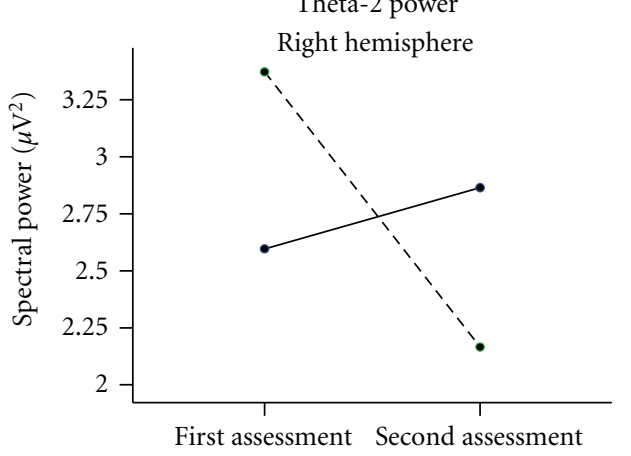

(a)

Theta-1 power at right hemisphere

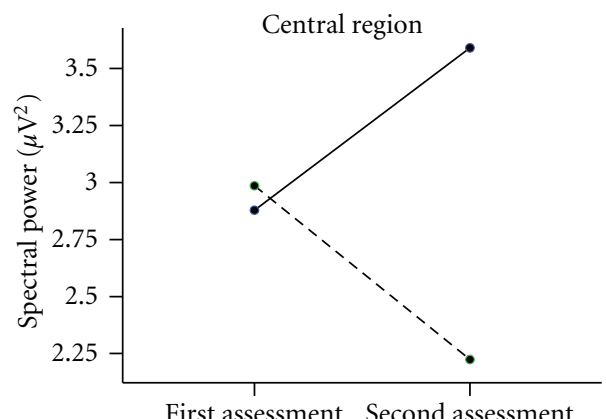

First assessment Second assessment

$$
\begin{aligned}
& \text { - Patients } \\
& --- \text { Controls }
\end{aligned}
$$

Delta-2 power

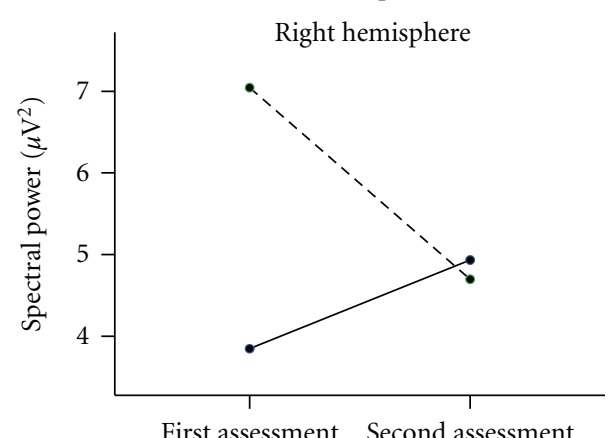

First assessment Second assessment
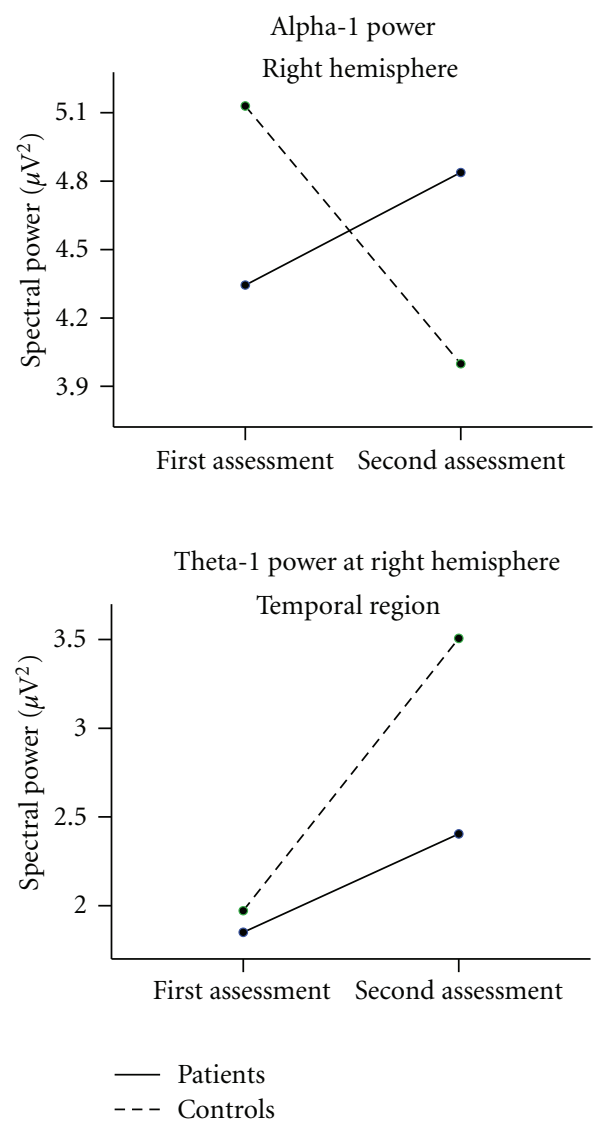

(b)

Figure 2: Group differences in dynamics of delta-1, delta-2, theta-2, and alpha-1 power in right hemisphere (a); group effects on dynamics of theta-1 power in central and temporal regions of right hemisphere (b).

4.1. Postoperative Beta Activity. Postoperative increase of beta power especially prominent in beta-1 band was a certain pathological phenomenon in our patient cohort. The similar postoperative increase of beta activity was previously reported after open heart operations [44] and on-pump coronary surgery [46]. Interestingly, increase of beta activity was reported in acute alcohol and heroin withdrawal, that is, conditions with pronounced neurochemical imbalances [48, 49]. Moreover, a "beta buzz" phenomenon with strong increase in EEG beta power was reported after administration of benzodiazepines and other GABA agonists $[27,56]$.

Porjesz and colleagues [27] explained the functional meaning of a "beta buzz" as a "slow gamma" activity. Normally, only excitatory neurons oscillate at beta frequency whereas inhibitory interneurons simultaneously oscillate at subharmonic gamma rate. GABA agonists synchronize excitatory and inhibitory neurons oscillations at beta frequency. In a range of studies (including our previous study 

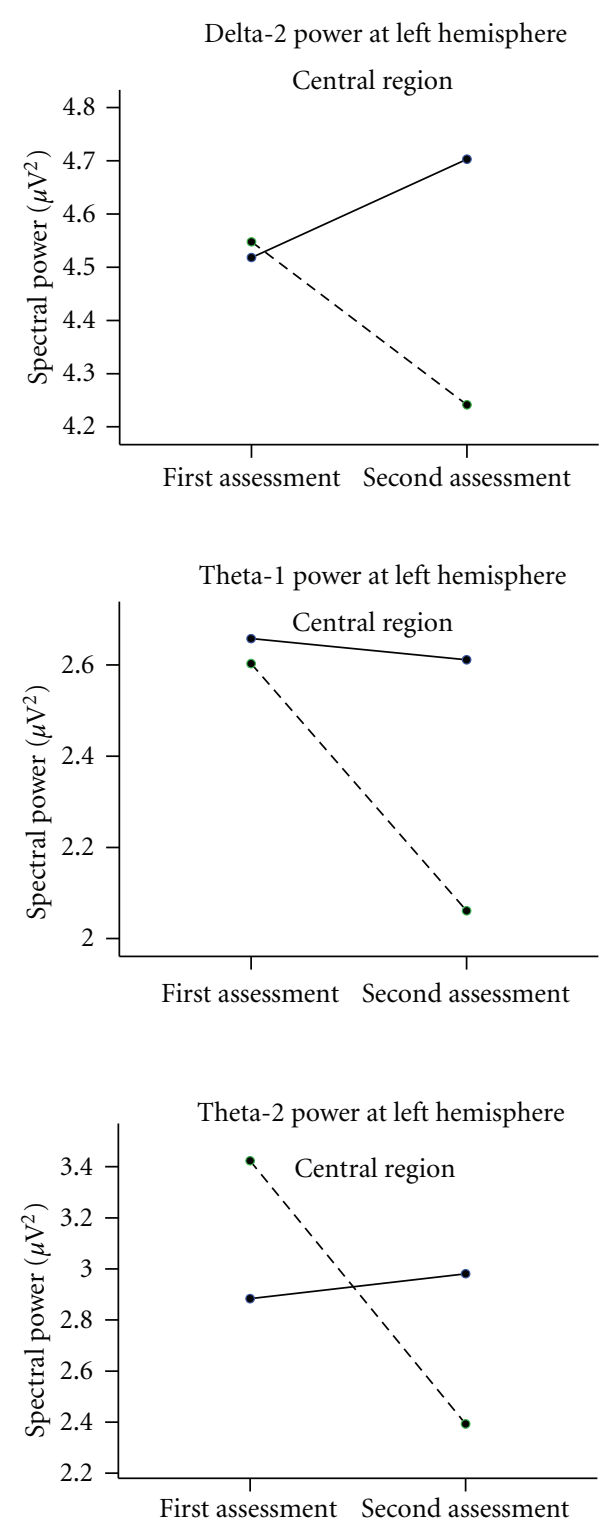

(a)

Theta-2 mean frequency at left hemisphere

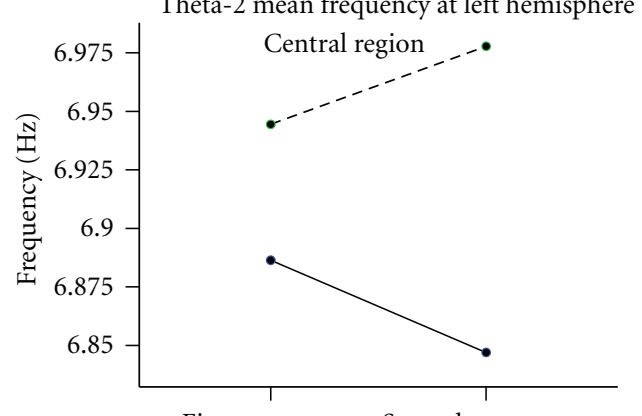

First assessment Second assessment

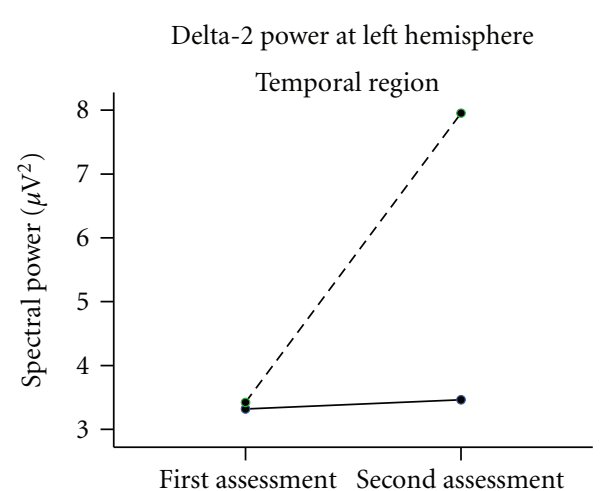

First assessment Second assessment
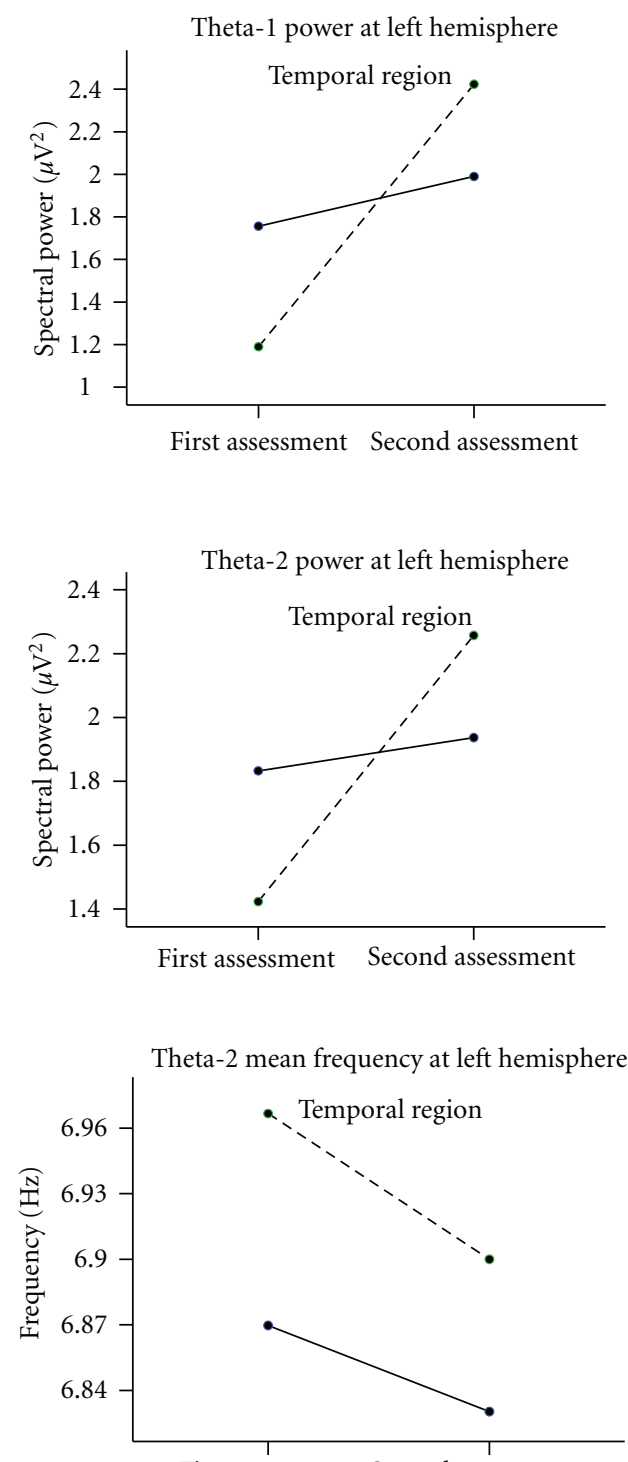

First assessment Second assessment —- Patients
-- Controls

(b)

FIGURE 3: Group differences in dynamics of delta-2, theta-1, and theta-2 power (a); theta-2 mean frequency (b) in central and temporal regions of left hemisphere. 

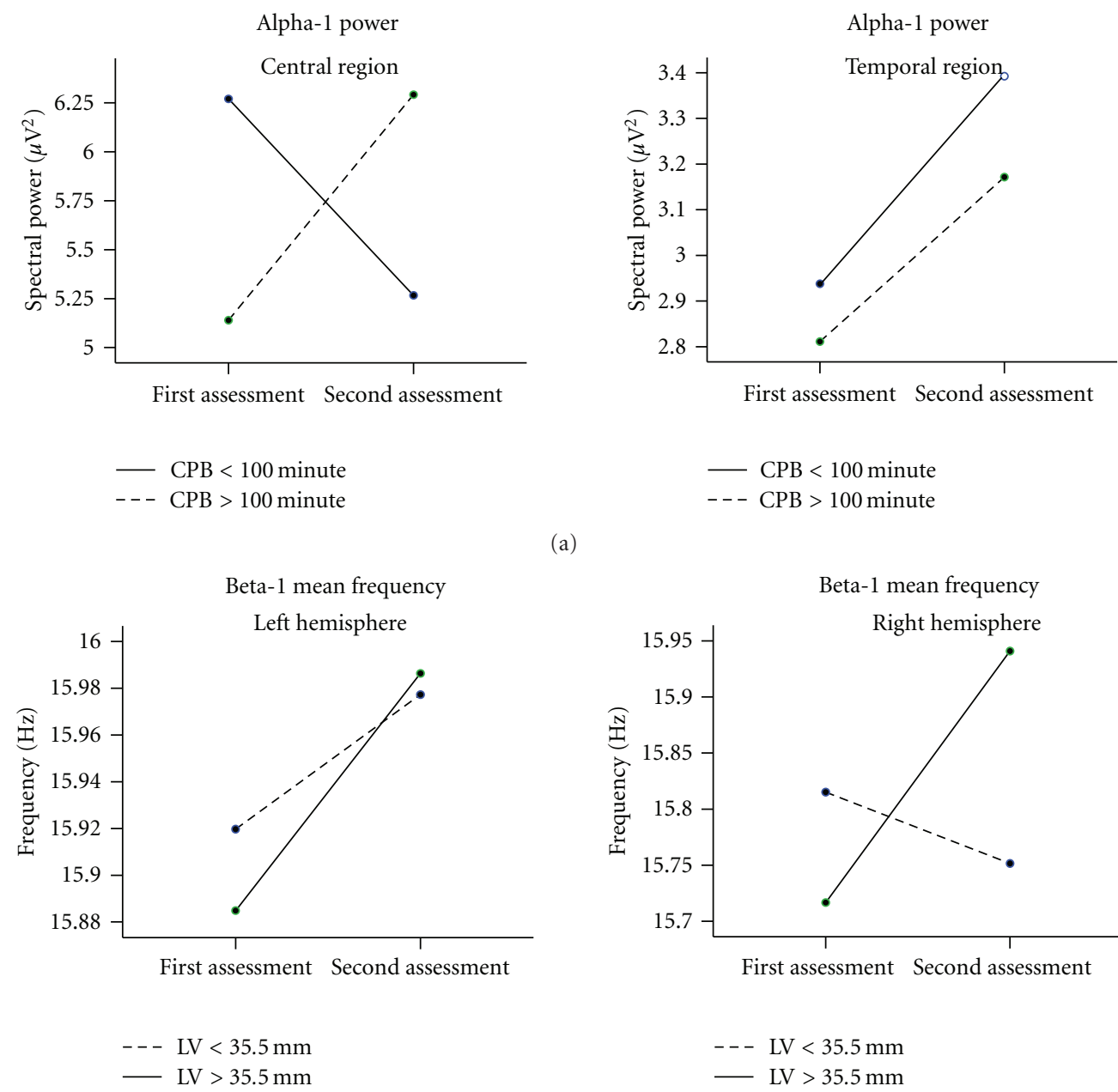

(a)

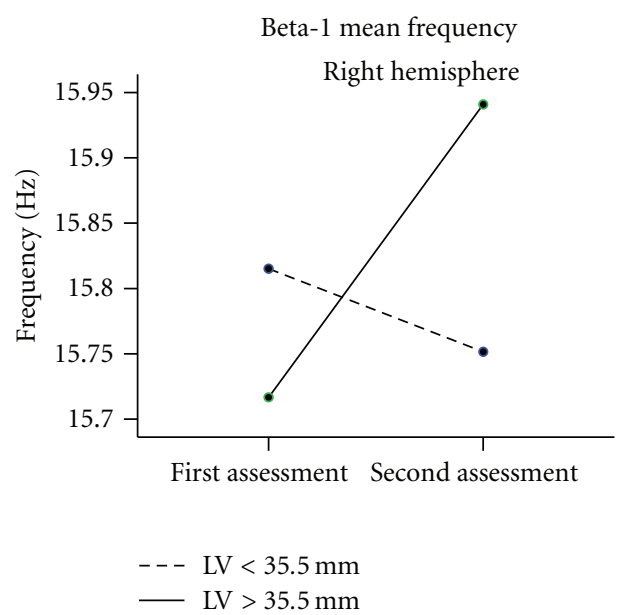

(b)

FIGURE 4: Effects of cardiopulmonary bypass length (a) and left ventricular size (b) on postoperative dynamics of brain electric activity.

of heroin addicts), strong association between beta power increase and slowing of psychomotor speed was observed [57-59]. Importantly, slowing of psychomotor speed is a very common postoperative deficit [11]. At the same time, postoperative increase of beta activity [46] and psychomotor slowing [11] were shown to be transitory, and this dynamics gives grounds to associate a postoperative "beta buzz" with global cortex edema and metabolism decrease reported by neuroimaging studies. Additional increase of beta-1 mean frequency in right hemisphere in patients with high risk of excessive embolism is logical, as previously we found asymmetrical distribution of emboli to right hemisphere in a similar cohort of patients [20]. The latter phenomenon may result from perfusion techniques.

4.2. Postoperative Alpha Activity. In agreement with almost all previous studies [44-47], we found prominent changes of alpha activity, especially, in fast (alpha-2) band. For instance, Hauser and colleagues [45] reported alpha-2 power decrease at 6-, 11-, and 44-day followups after open heart operations in children. Slowing of alpha-rhythm (alpha activity in occipital region) at followup was consistently reported in previous studies of postoperative EEG changes as well [44, 47]. Nevertheless, healthy subjects in our study demonstrated the similar decrease of alpha-2 activity at second assessment [52]. In addition, both patient and control groups showed analogous widespread alpha-2 mean frequency and localized alpha-1 mean frequency changes. Importantly, two more studies reported significant decrease of alpha activity and increase of peak alpha frequency in healthy subjects during repeated EEG evaluations $[51,60]$. Thus, decrement of alpha activity along with alpha mean frequency shifts at repeated EEG is regularly observed in both healthy subjects and cardiac surgery patients. Therefore, alpha activity changes in our patient cohort appear to represent at least partially a physiological phenomenon.

It is widely known, that alpha rhythm is a dominating activity in adult subjects during eyes closed "resting" condition. In healthy young subjects, alpha-2 activity (10$12 \mathrm{~Hz}$ ) dominates at occipital derivations, and the source of alpha-2 oscillations is lateralized to right hemisphere [61]. Previously, alpha rhythm was commonly considered 
as an idling rhythm of visual cortex as it was blocked by eyes opening. However, this view is contradicted by the stimulus-related enhancement of alpha activity, which was consistently shown in a range of studies. For instance, alpha rhythm maximally synchronizes at rhythmic light stimulation, and in healthy subjects occipital cortex responds with $10-12 \mathrm{~Hz}$ wave forms $[62,63]$. Intensive contemplating of complex pictures induces prominent increase of interhemispheric coherence of alpha-oscillations at occipital and posterior temporal derivations, and memorizing of the same pictures does not affect alpha activity coherence in comparison with "resting" background [53]. Enhancement of synchronization of alpha activity after simple auditory stimuli (tones) was consistently shown in a range of studies as well $[28,64,65]$. Overall, the cited studies evidenced that alpha activity is an intrinsic component of cortex cognitive processing rather than an "idling" cortex phenomenon. Not surprisingly, spectral characteristics of alpha-rhythm and overall spontaneous alpha-activity were consistently shown to highly correlate with a range of cognitive abilities $[51,66,67]$.

Laufs and colleagues [68] showed positive correlations between alpha-oscillations and activation of cingulate and occipital cortex at fMRI scans during "resting" eyes closed condition. Sadaghiani et al. [36] found similar positive associations between global alpha-2 activity power at eyes closed resting state and activity at a network comprising dorsal anterior cingulated cortex, anterior insula, anterior prefrontal cortex, and thalamus. The latter brain structures are commonly designated as a "default-mode" network, which maximally activates during "resting" state. We could not identify MRI studies, which repeatedly evaluated a default-mode network functioning in healthy subjects. We just may hypothesize that activity of the former decreased at followup in our patients and healthy subjects, and therefore alpha- 2 activity power decreased as well. As it was cited earlier, alpha oscillations are an intrinsic component of cognitive evoked potentials, and decrease of amplitude of the latter is a widely known phenomenon $[48,49]$. Therefore, at least partially, alpha power decrease in our patient cohort appear to be physiological. Perhaps, only the elevation of alpha-1 power in central derivations in patients after prolonged bypass may be hypothesized to be pathological; however, further research is needed to determine the significance of the latter finding. We hope to elucidate the nature of alpha activity reduction in our patient cohort after analyses of interrelationships between postoperative EEG data and performance on cognitive tests.

4.3. Postoperative Delta and Theta Activity. Both patient and control groups demonstrated significant changes of slowwave activity at followup assessment. Important, that healthy controls showed increase of delta-2, theta-1, and theta-2 power in left temporal region (T3) at followup. Patients did not demonstrate comparable dynamics of regional slowwave activity in left hemisphere, and absence of the latter physiological EEG changes may be suggested to be a deficient neurological sign. As left hemisphere and posterior brain cortex were consistently shown to be highly vulnerable to ischemia during cardiac operations [7, 19, 69-72], we discuss the left temporal region deficit in our patient cohort in detail.

A range of experimental studies consistently demonstrated that delta/theta activity is an intrinsic component of information processing in normal human brain [30, 7375]. At present, it is widely accepted that theta activity synchronizes during mnemonic processes in humans [73, 75]. For instance, Kirk and Mackay [75] showed that theta activity synchronized left temporally during digit span task and right temporally during spatial memory task. Complex calculations and concept formation were shown to be associated with prominent synchronization of delta activity over frontal and temporal regions as well $[30,75]$. Although visual and auditory stimuli usually evoke a broadband response, delta-theta oscillations tend to demonstrate larger synchronization during processing of auditory information as opposed to alpha activity, which predominates during visual tasks over posterior brain regions [53, 76]. During eyes closed "resting" condition the source of delta and theta activity localizes anterior and somewhat leftward from midline, that is, closer to auditory cortex in comparison with alpha activity [61]. Importantly, Corsi-Cabrera and colleagues [50] showed significant increase of theta power at followup in their study of healthy women.

The cited above neurophysiological studies give grounds to hypothesize that electric brain activity in healthy subjects shifted from "visualizing" regimen during primary assessment to "internal speech" regimen, and therefore slow-wave activity at left temporal region increased along with concomitant alpha activity decrease. Patients did not demonstrate this physiological shift of electric brain activity probably due to ischemic alterations in left temporal cortex. At least two neuroimaging studies showed localized postoperative dysfunction of left temporal cortex in patients after on-pump coronary surgery [19, 72]. Moreover, verbal memory decline is the most common postoperative cognitive deficit in cardiac surgery patients [11, 19]. Interestingly, Zeitlhofer and colleagues [44] reported a trend for more pronounced EEG changes in left hemisphere after open heart surgery.

In addition, we observed significant postoperative increase of delta- 1 and delta- 2 mean frequencies in all brain regions without concomitant generalized changes of delta power. However, only dynamics of delta-1 mean frequency differed between patients and controls. A trend for region-specific postoperative elevation of delta-2 power was observed. Analyses at separate leads showed significant increase of delta-2 and theta activity in posterior derivations of right hemisphere after open heart operations. The latter EEG changes in the patient group differed significantly from controls, which showed the most prominent decrease of delta and theta-2 activity in this region. It should be noted that Vanninen and colleagues [47] found similar postoperative increase of delta activity in right posterior region (bipolar derivation T6-O2), along with increase of theta activity in bilateral central derivations. Moreover, overall mean frequency significantly slowed in right hemisphere in their study. 
Slow-wave activity was traditionally associated with compromised brain states, and therefore was considered as an unambiguous pathological sign $[37,77]$. Thatcher and colleagues [31] found opposite association between increase of delta amplitude and the severity of white matter alterations in patients after brain injury. It may be hypothesized, that generalized shift of delta-1 mean frequency and elevation of slow-wave activity in posterior right region were pathological in our patient cohort. Further research is needed in order to identify the mechanisms of slow-wave activity changes after cardiac operations.

4.4. Limitations of the Study. The small number of patient and control subjects makes the present results preliminary. A somewhat imbalanced gender distribution between patient and control groups may be a source of result bias in the present study, as gender was recently shown to affect brain electric activity characteristics. Preoperative abnormalities of brain electric activity in patients in comparison with healthy controls is the other limitation of this study. It should be noted that premorbid cognitive and electrophysiological dysfunction is a common problem for studies investigating patients with chronic diseases as good general health is an important contributor to normal brain functioning. Absence of direct measurements of intraoperative cerebral microembolism is an important limitation as well, and further research is needed in order to determine effects of intraoperative emboli on postoperative brain electrophysiology.

\section{Conclusions}

Both pathological and physiological changes of brain electric activity were observed after open heart operations. Generalized postoperative increase of beta power most prominent in beta-1 band was an unambiguous pathological sign of postoperative cortex dysfunction, probably, manifesting due to gamma-activity slowing ("beta buzz" symptom). Generalized increase of delta-1 mean frequency along with increase of slow-wave activity in right posterior region may be hypothesized to be a consequence of intraoperative ischemia as well. At the same time, significant changes of alpha activity were observed in both patient and control groups, and, therefore, may be considered as physiological. Unexpectedly, controls showed prominent increase of electric activity in left temporal region whereas patients were deficient in left hemisphere activity in comparison with controls at postoperative followup. Further research is needed in order to determine the true neurological meaning of the EEG findings after on-pump operations.

\section{References}

[1] D. N. F. Harris, A. Oatridge, D. Dob, P. L. C. Smith, K. M. Taylor, and G. M. Bydder, "Cerebral swelling after normothermic cardiopulmonary bypass," Anesthesiology, vol. 88, no. 2, pp. 340-345, 1998.

[2] A. Jacobs, M. Neveling, M. Horst et al., "Alterations of neuropsychological function and cerebral glucose metabolism after cardiac surgery are not related only to intraoperative microembolic events," Stroke, vol. 29, no. 3, pp. 660-667, 1998.

[3] R. E. Anderson, T. Q. Li, T. Hindmarsh, G. Settergren, and J. Vaage, "Increased extracellular brain water after coronary artery bypass grafting is avoided by off-pump surgery," Journal of Cardiothoracic and Vascular Anesthesia, vol. 13, no. 6, pp. 698-702, 1999.

[4] M. Bendszus, W. Reents, D. Franke et al., "Brain damage after coronary artery bypass grafting," Archives of Neurology, vol. 59, no. 7, pp. 1090-1095, 2002.

[5] L. Restrepo, R. J. Wityk, M. A. Grega et al., "Diffusion- and perfusion-weighted magnetic resonance imaging of the brain before and after coronary artery bypass grafting surgery," Stroke, vol. 33, no. 12, pp. 2909-2915, 2002.

[6] S. C. Knipp, N. Matatko, H. Wilhelm et al., "Evaluation of brain injury after coronary artery bypass grafting. A prospective study using neuropsychological assessment and diffusion-weighted magnetic resonance imaging," European Journal of Cardio-thoracic Surgery, vol. 25, no. 5, pp. 791-800, 2004.

[7] E. Stolz, T. Gerriets, A. Kluge, W. P. Klövekorn, M. Kaps, and G. Bachmann, "Diffusion-weighted magnetic resonance imaging and neurobiochemical markers after aortic valve replacement: implications for future neuroprotective trials?" Stroke, vol. 35, no. 4, pp. 888-892, 2004.

[8] T. F. Floyd, P. N. Shah, C. C. Price et al., "Clinically silent cerebral ischemic events after cardiac surgery: their incidence, regional vascular occurrence, and procedural dependence," Annals of Thoracic Surgery, vol. 81, no. 6, pp. 2160-2166, 2006.

[9] K. A. Sotaniemi, "Clinical and prognostic correlates of EEG in open-heart surgery patients," Journal of Neurology Neurosurgery and Psychiatry, vol. 43, no. 10, pp. 941-947, 1980.

[10] C. Bergh, M. Bäckström, H. Jönsson, L. Havinder, and P. Johnsson, "In the eye of both patient and spouse: memory is poor 1 to 2 years after coronary bypass and angioplasty," Annals of Thoracic Surgery, vol. 74, no. 3, pp. 689-693, 2002.

[11] L. A. Bokeriia, E. Z. Golukhova, A. G. Polunina, D. M. Davydov, and A. V. Begachev, "Neural correlates of cognitive dysfunction after cardiac surgery," Brain Research Reviews, vol. 50, no. 2, pp. 266-274, 2005.

[12] J. D. Salazar, R. J. Wityk, M. A. Grega et al., "Stroke after cardiac surgery: short- and long-term outcomes," Annals of Thoracic Surgery, vol. 72, no. 4, pp. 1195-1201, 2001.

[13] R. J. Wityk, M. A. Goldsborough, A. Hillis et al., "Diffusionand perfusion-weighted brain magnetic resonance imaging in patients with neurologic complications after cardiac surgery," Archives of Neurology, vol. 58, no. 4, pp. 571-576, 2001.

[14] D. S. Likosky, C. A. S. Marrin, L. R. Caplan et al., "Determination of etiologic mechanisms of strokes secondary to coronary artery bypass graft surgery," Stroke, vol. 34, no. 12, pp. 28302834, 2003.

[15] D. Barbut, Y. W. Lo, J. P. Gold et al., "Impact of embolization during coronary artery bypass grafting on outcome and length of stay," Annals of Thoracic Surgery, vol. 63, no. 4, pp. 998$1002,1997$.

[16] S. Sylivris, C. Levi, G. Matalanis et al., "Pattern and significance of cerebral microemboli during coronary artery bypass grafting," Annals of Thoracic Surgery, vol. 66, no. 5, pp. 16741678, 1998.

[17] L. A. Bokeriia, E. Z. Golukhova, and A. G. Polunina, "Postoperative delirium in cardiac operations: microembolic load is an important factor," Annals of Thoracic Surgery, vol. 88, no. 1, pp. 349-350, 2009. 
[18] S. J. Fearn, R. Pole, K. Wesnes, E. B. Faragher, T. L. Hooper, and C. N. McCollum, "Cardiopulmonary support and physiology. Cerebral injury during cardiopulmonary bypass: emboli impair memory," Journal of Thoracic and Cardiovascular Surgery, vol. 121, no. 6, pp. 1150-1160, 2001.

[19] J. D. Lee, S. J. Lee, W. T. Tsushima et al., "Benefits of off-pump bypass on neurologic and clinical morbidity: a prospective randomized trial," Annals of Thoracic Surgery, vol. 76, no. 1, pp. 18-26, 2003.

[20] L. A. Bokeriia, E. Z. Golukhova, N. Y. Breskina et al., "Asymmetric cerebral embolic load and postoperative cognitive dysfunction in cardiac surgery," Cerebrovascular Diseases, vol. 23, no. 1, pp. 50-56, 2007.

[21] J. Stygall, S. P. Newman, G. Fitzgerald et al., "Cognitive Change 5 Years after Coronary Artery Bypass Surgery," Health Psychology, vol. 22, no. 6, pp. 579-586, 2003.

[22] R. E. Clark, J. Brillman, D. A. Davis, M. R. Lovell, T. R. P. Price, and G. J. Magovern, "Microemboli during coronary artery bypass grafting: genesis and effect on outcome," Journal of Thoracic and Cardiovascular Surgery, vol. 109, no. 2, pp. 249258, 1995.

[23] Y. Abu-Omar, L. Balacumaraswami, D. W. Pigott, P. M. Matthews, and D. P. Taggart, "Solid and gaseous cerebral microembolization during off-pump, on-pump, and open cardiac surgery procedures," Journal of Thoracic and Cardiovascular Surgery, vol. 127, no. 6, pp. 1759-1765, 2004.

[24] S. K. Brækken, I. Reinvang, D. Russell, R. Brucher, and J. L. Svennevig, "Association between intraoperative cerebral microembolic signals and postoperative neuropsychological deficit: comparison between patients with cardiac valve replacement and patients with coronary artery bypass grafting," Journal of Neurology Neurosurgery and Psychiatry, vol. 65, no. 4, pp. 573-576, 1998.

[25] M. J. Neville, J. Butterworth, R. L. James, J. W. Hammon, and D. A. Stump, "Similar neurobehavioral outcome after valve or coronary artery operations despite differing carotid embolic counts," Journal of Thoracic and Cardiovascular Surgery, vol. 121, no. 1, pp. 125-136, 2001.

[26] J. Bucerius, J. F. Gummert, M. A. Borger et al., "Predictors of delirium after cardiac surgery delirium: effect of beating-heart (off-pump) surgery," Journal of Thoracic and Cardiovascular Surgery, vol. 127, no. 1, pp. 57-64, 2004.

[27] B. Porjesz, L. Almasy, H. J. Edenberg et al., "Linkage disequilibrium between the beta frequency of the human EEG and a GABAA receptor gene locus," Proceedings of the National Academy of Sciences of the United States of America, vol. 99, no. 6, pp. 3729-3733, 2002.

[28] E. Başar, C. Başar-Eroglu, S. Karakaş, and M. Schürmann, "Gamma, alpha, delta, and theta oscillations govern cognitive processes," International Journal of Psychophysiology, vol. 39, no. 2-3, pp. 241-248, 2000.

[29] J. L. Cantero, M. Atienza, and R. M. Salas, "Human alpha oscillations in wakefulness, drowsiness period, and REM sleep: different electroencephalographic phenomena within the alpha band," Neurophysiologie Clinique, vol. 32, no. 1, pp. 54-71, 2002.

[30] T. Harmony, T. Fernández, J. Silva et al., "EEG delta activity: an indicator of attention to internal processing during performance of mental tasks," International Journal of Psychophysiology, vol. 24, no. 1-2, pp. 161-171, 1996.

[31] R. W. Thatcher, D. North, and C. Biver, "EEG and intelligence: relations between EEG coherence, EEG phase delay and power," Clinical Neurophysiology, vol. 116, no. 9, pp. 21292141, 2005.
[32] E. Marosi, H. Rodrìguez, T. Harmony et al., "Broad band spectral EEG parameters correlated with different IQ measurements," International Journal of Neuroscience, vol. 97, no. 1-2, pp. 17-27, 1999.

[33] A. G. Polunina and D. M. Davydov, "EEG correlates of Wechsler Adult Intelligence Scale," International Journal of Neuroscience, vol. 116, no. 10, pp. 1231-1248, 2006.

[34] H. Laufs, K. Krakow, P. Sterzer et al., "Electroencephalographic signatures of attentional and cognitive default modes in spontaneous brain activity fluctuations at rest," Proceedings of the National Academy of Sciences of the United States of America, vol. 100, no. 19, pp. 11053-11058, 2003.

[35] L. L. Beason-Held, M. A. Kraut, and S. M. Resnick, "Stability of default-mode network activity in the aging brain," Brain Imaging and Behavior, vol. 3, no. 2, pp. 123-131, 2009.

[36] S. Sadaghiani, R. Scheeringa, K. Lehongre, B. Morillon, A. L. Giraud, and A. Kleinschmidt, "Intrinsic connectivity networks, alpha oscillations, and tonic alertness: a simultaneous electroencephalography/functional magnetic resonance imaging study," Journal of Neuroscience, vol. 30, no. 30, pp. 10243-10250, 2010.

[37] G. Florence, J. M. Guerit, and B. Gueguen, "Electroencephalography (EEG) and somatosensory evoked potentials (SEP) to prevent cerebral ischaemia in the operating room," Neurophysiologie Clinique, vol. 34, no. 1, pp. 17-32, 2004.

[38] L. D. Gugino, L. S. Aglio, and A. Yli-Hankala, "Monitoring the electroencephalogram during bypass procedures," Seminars in Cardiothoracic and Vascular Anesthesia, vol. 8, no. 2, pp. 61-83, 2004.

[39] L. D. Gugino, R. J. Chabot, L. S. Aglio, S. Aranki, R. Dekkers, and R. Maddi, "QEEG changes during cardiopulmonary bypass: relationship to postoperative neuropsychological function," Clinical EEG Electroencephalography, vol. 30, no. 2, pp. 53-63, 1999.

[40] I. Toner, K. M. Taylor, S. Newman, and P. L. C. Smith, "Cerebral functional deficit in cardiac surgical patients investigated with P300 and neuropsychological tests," in Functional Neuroscience, C. Barber, Ed., Suppement 46, pp. 243-251, Elsevier, Amsterdam, The Netherlands, 1996.

[41] J. Kilo, M. Czerny, M. Gorlitzer et al., "Cardiopulmonary bypass affects cognitive brain function after coronary artery bypass grafting," Annals of Thoracic Surgery, vol. 72, no. 6, pp. 1926-1932, 2001.

[42] D. Zimpfer, M. Czerny, J. Kilo et al., "Cognitive deficit after aortic valve replacement," Annals of Thoracic Surgery, vol. 74, no. 2, pp. 407-412, 2002.

[43] M. Grimm, D. Zimpfer, M. Czerny et al., "Neurocognitive deficit following mitral valve surgery," European Journal of Cardio-thoracic Surgery, vol. 23, no. 3, pp. 265-271, 2003.

[44] J. Zeitlhofer, B. Saletu, P. Anderer et al., "Topographic brain mapping of EEG before and after open-heart surgery," Neuropsychobiology, vol. 20, no. 1, pp. 51-56, 1988.

[45] E. Hauser, R. Seidl, D. Rohrbach, I. Hartl, M. Marx, and M. Wimmer, "Quantitative EEG before and after open heart surgery in children. A significant decrease in the beta and alpha bands postoperatively," Electroencephalography and Clinical Neurophysiology, vol. 87, no. 5, pp. 284-290, 1993.

[46] I. Toner, K. M. Taylor, S. Newman, and P. L. C. Smith, "Cerebral functional changes following cardiac surgery: neuropsychological and EEG assessment," European Journal of Cardio-thoracic Surgery, vol. 13, no. 1, pp. 13-20, 1998.

[47] R. Vanninen, M. Äikiä, M. Könönen et al., "Subclinical cerebral complications after coronary artery bypass grafting: prospective analysis with magnetic resonance imaging, 
quantitative electroencephalography, and neuropsychological assessment," Archives of Neurology, vol. 55, no. 5, pp. 618-627, 1998.

[48] J. Polich and A. Kok, "Cognitive and biological determinants of P300: an integrative review," Biological Psychology, vol. 41, no. 2, pp. 103-146, 1995.

[49] C. Ranganath and G. Rainer, "Neural mechanisms for detecting and remembering novel events," Nature Reviews Neuroscience, vol. 4, no. 3, pp. 193-202, 2003.

[50] M. Corsi-Cabrera, L. Galindo-Vilchis, Y. del-Río-Portilla, C. Arce, and J. Ramos-Loyo, "Within-subject reliability and inter-session stability of EEG power and coherent activity in women evaluated monthly over nine months," Clinical Neurophysiology, vol. 118, no. 1, pp. 9-21, 2007.

[51] E. Angelakis, J. F. Lubar, S. Stathopoulou, and J. Kounios, "Peak alpha frequency: an electroencephalographic measure of cognitive preparedness," Clinical Neurophysiology, vol. 115, no. 4, pp. 887-897, 2004.

[52] A. G. Polunina, N. P. Lefterova, and A. V. Begachev, "Changes of spectral EEG parameters in normals at two week followup," Zh Nevrol Psyikhiatr Im SS Korsakova, vol. 111, no. 2, pp. 64-71, 2011.

[53] H. Petsche, S. Kaplan, A. Von Stein, and O. Filz, "The possible meaning of the upper and lower alpha frequency ranges for cognitive and creative tasks," International Journal of Psychophysiology, vol. 26, no. 1-3, pp. 77-97, 1997.

[54] W. Klimesch, "EEG alpha and theta oscillations reflect cognitive and memory performance: a review and analysis," Brain Research Reviews, vol. 29, no. 2-3, pp. 169-195, 1999.

[55] N. P. Lefterova and A. V. Begachev, "Size of left cardiac chambers correlates with cerebral microembolic load in open heart operations," Cardiology Research and Practice, vol. 2010, Article ID 143679, 2010.

[56] L. D. Gugino, R. J. Chabot, L. S. Prichep, E. R. John, V. Formanek, and L. S. Aglio, "Quantitative EEG changes associated with loss and return of consciousness in healthy adult volunteers anaesthetized with propofol or sevoflurane," British Journal of Anaesthesia, vol. 87, no. 3, pp. 421-428, 2001.

[57] G. B. Kaplan, D. J. Greenblatt, B. L. Ehrenberg, J. E. Goddard, J. S. Harmatz, and R. I. Shader, "Differences in pharmacodynamics but not pharmacokinetics between subjects with panic disorder and healthy subjects after treatment with a single dose of alprazolam," Journal of Clinical Psychopharmacology, vol. 20, no. 3, pp. 338-346, 2000.

[58] L. M. Lucchesi, S. Pompéia, G. M. Manzano et al., "Flunitrazepam-induced changes in neurophysiological, behavioural, and subjective measures used to assess sedation," Progress in Neuro-Psychopharmacology and Biological Psychiatry, vol. 27, no. 3, pp. 525-533, 2003.

[59] A. G. Polunina and D. M. Davydov, "EEG spectral power and mean frequencies in early heroin abstinence," Progress in Neuro-Psychopharmacology and Biological Psychiatry, vol. 28, no. 1, pp. 73-82, 2004.

[60] T. Fernández, T. Harmony, M. Rodríguez, A. Reyes, E. Marosi, and J. Bernal, "Test-retest reliability of EEG spectral parameters during cognitive tasks: I. Absolute and relative power," International Journal of Neuroscience, vol. 68, no. 3-4, pp. 255-261, 1993.

[61] I. Kondakor, D. Brandeis, J. Wackermann et al., "Multichannel EEG fields during and without visual input: frequency domain model source locations and dimensional complexities," Neuroscience Letters, vol. 226, no. 1, pp. 49-52, 1997.
[62] M. Schürmann and E. Başar, "Functional aspects of alpha oscillations in the EEG," International Journal of Psychophysiology, vol. 39, no. 2-3, pp. 151-158, 2000.

[63] Z. Wu and D. Yao, "The influence of cognitive tasks on different frequencies steady-state visual evoked potentials," Brain Topography, vol. 20, no. 2, pp. 97-104, 2007.

[64] V. Kolev, J. Yordanova, M. Schürmann, and E. Başar, "Increased frontal phase-locking of event-related alpha oscillations during task processing," International Journal of Psychophysiology, vol. 39, no. 2-3, pp. 159-165, 2000.

[65] W. R. Gruber, W. Klimesch, P. Sauseng, and M. Doppelmayr, "Alpha phase synchronization predicts P1 end N1 latency and amplitude size," Cerebral Cortex, vol. 15, no. 4, pp. 371-377, 2005.

[66] I. V. Maltseva and Y. P. Masloboev, "Alpha rhythm parameters and short-term memory span," International Journal of Psychophysiology, vol. 26, no. 1-3, pp. 369-380, 1997.

[67] C. R. Clark, M. D. Veltmeyer, R. J. Hamilton et al., "Spontaneous alpha peak frequency predicts working memory performance across the age span," International Journal of Psychophysiology, vol. 53, no. 1, pp. 1-9, 2004.

[68] H. Laufs, K. Krakow, P. Sterzer et al., "Electroencephalographic signatures of attentional and cognitive default modes in spontaneous brain activity fluctuations at rest," Proceedings of the National Academy of Sciences of the United States of America, vol. 100, no. 19, pp. 11053-11058, 2003.

[69] G. S. Weinstein, "Left hemispheric strokes in coronary surgery: implications for end-hole aortic cannulas," Annals of Thoracic Surgery, vol. 71, no. 1, pp. 128-132, 2001.

[70] D. Barbut, D. Grassineau, E. Lis, L. Heier, G. S. Hartman, and O. W. Isom, "Posterior distribution of infarcts in strokes related to cardiac operations," Annals of Thoracic Surgery, vol. 65, no. 6, pp. 1656-1659, 1998.

[71] R. R. Leker, A. Pollak, O. Abramsky, and T. Ben-Hur, "Abundance of left hemispheric embolic strokes complicating coronary angiography and PTCA," Journal of Neurology Neurosurgery and Psychiatry, vol. 66, no. 1, pp. 116-117, 1999.

[72] L. S. Rasmussen, B. Sperling, H. H. Abildstrøm, and J. T. Moller, "Neuron loss after coronary artery bypass detected by SPECT estimation of benzodiazepine receptors," Annals of Thoracic Surgery, vol. 74, no. 5, pp. 1576-1580, 2002.

[73] W. Klimesch, "EEG alpha and theta oscillations reflect cognitive and memory performance: a review and analysis," Brain Research Reviews, vol. 29, no. 2-3, pp. 169-195, 1999.

[74] J. A. González-Hernández, C. Pita-Alcorta, I. Cedeño et al., "Wisconsin card sorting test synchronizes the prefrontal, temporal and posterior association cortex in different frequency ranges and extensions," Human Brain Mapping, vol. 17, no. 1, pp. 37-47, 2002.

[75] I. J. Kirk and J. C. Mackay, "The role of theta-range oscillations in synchronising and integrating activity in distributed mnemonic networks," Cortex, vol. 39, no. 4-5, pp. 993-1008, 2003.

[76] B. Voytek, R. T. Canolty, A. Shestyuk, N. E. Crone, J. Parvizi, and R. T. Knight, "Shifts in gamma phase-amplitude coupling frequency from theta to alpha over posterior cortex during visual tasks," Frontiers in Human Neuroscience, vol. 4, article 191, 2010.

[77] A. Fernández-Bouzas, T. Harmony, J. Bosch et al., "Sources of abnormal EEG activity in the presence of brain lesions," Clinical EEG Electroencephalography, vol. 30, no. 2, pp. 46-52, 1999. 


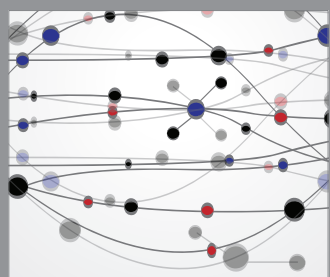

The Scientific World Journal
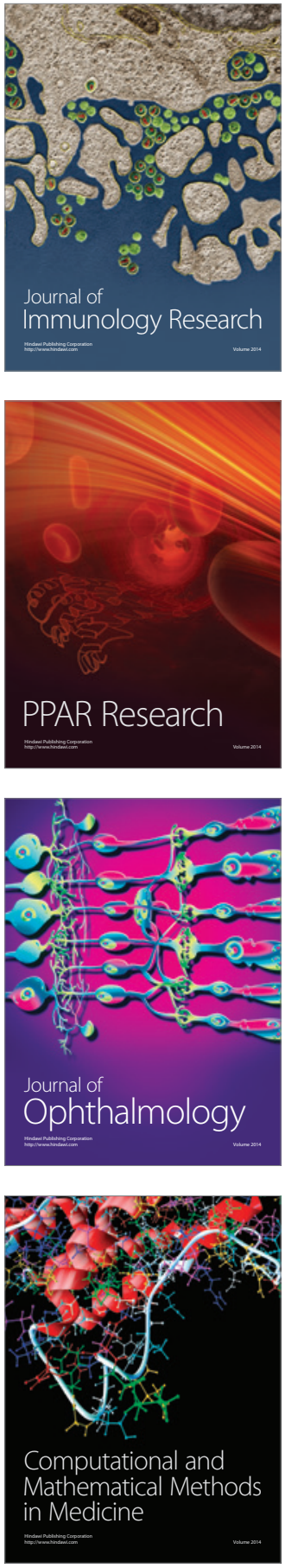

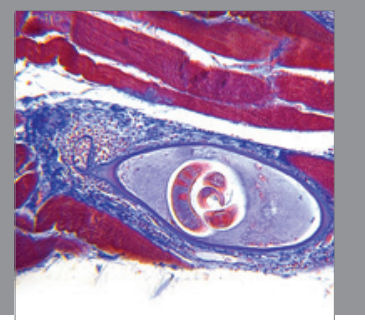

Gastroenterology

Research and Practice
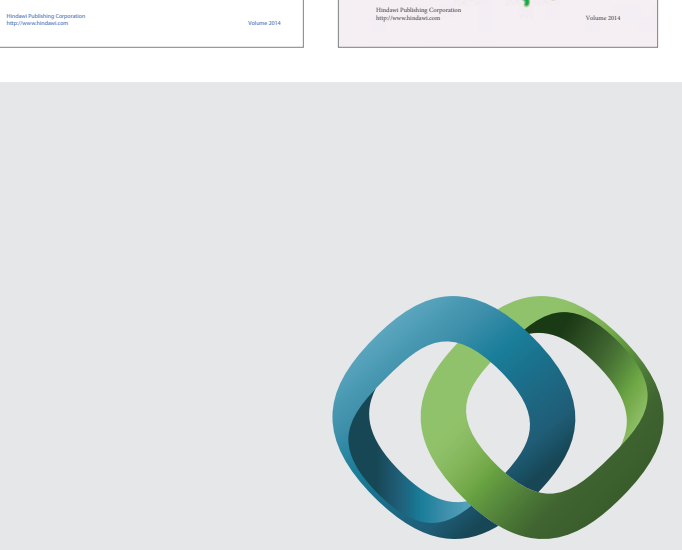

\section{Hindawi}

Submit your manuscripts at

http://www.hindawi.com
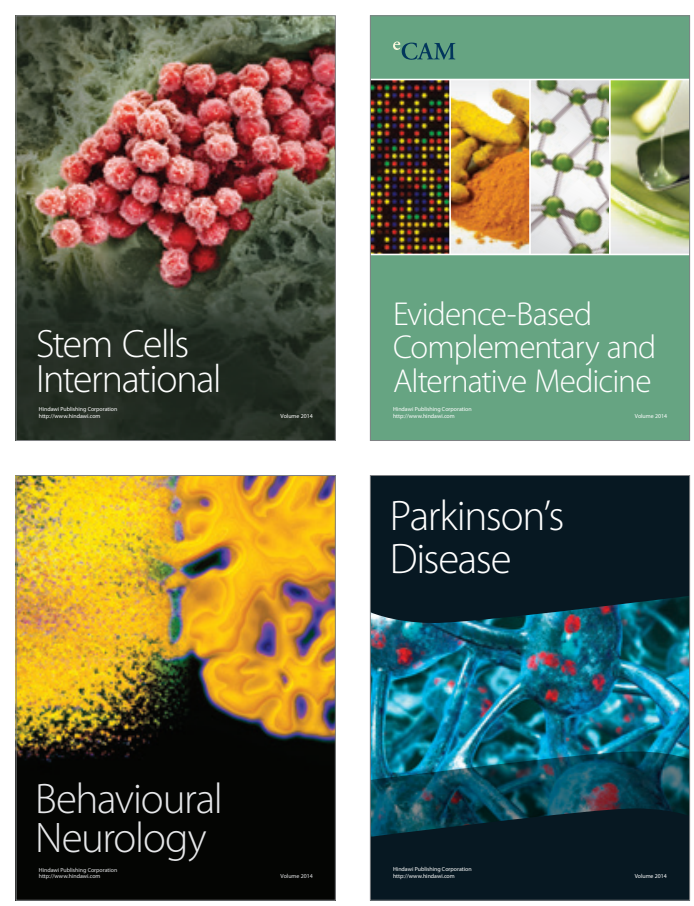

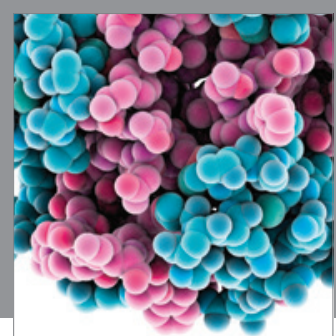

Journal of
Diabetes Research

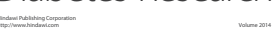

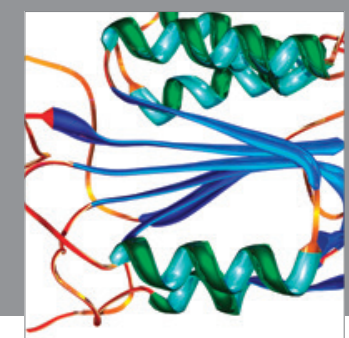

Disease Markers
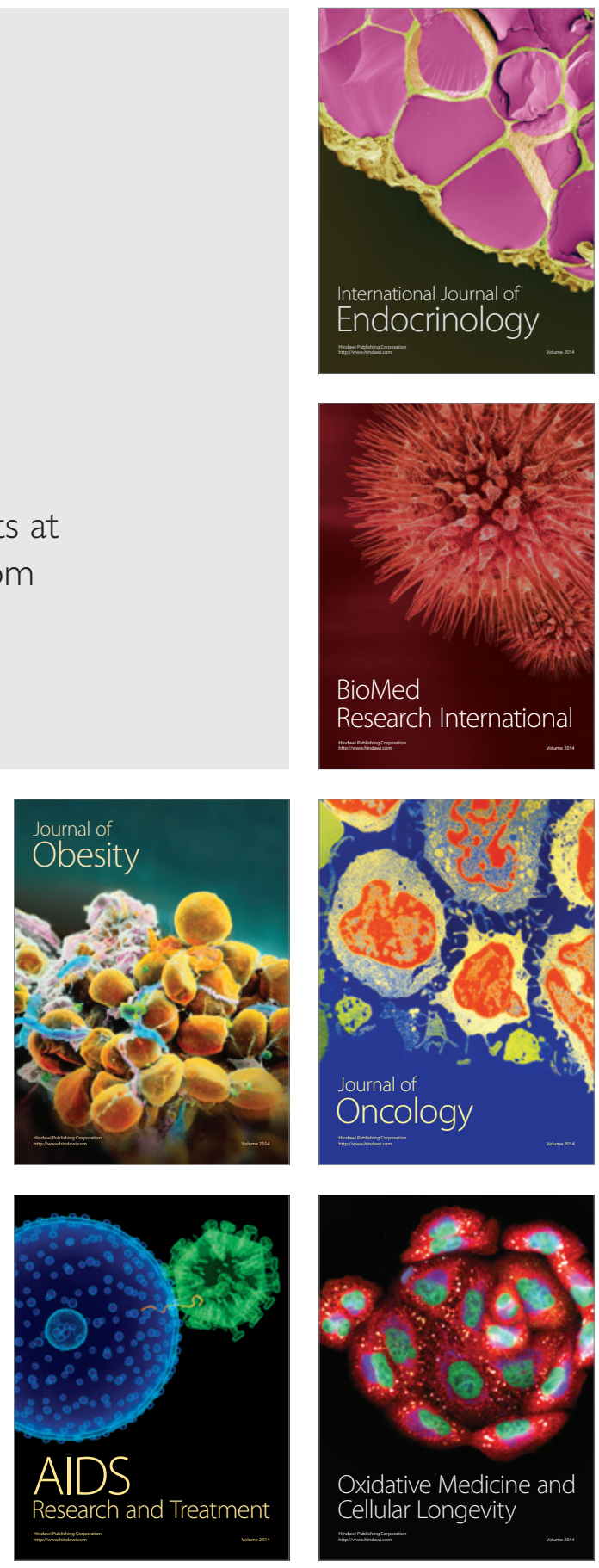